\title{
Indicators of zinc status at the population level: a review of the evidence
}

\author{
Rosalind S. Gibson ${ }^{1}$, Sonja Y. Hess ${ }^{2}$, Christine Hotz ${ }^{3}$ and Kenneth H. Brown ${ }^{2,4}$ \\ ${ }^{1}$ Department of Hunan Nutrition, University of Otago, Union Street, PO Box 56, Dunedin 9015, New Zealand \\ ${ }^{2}$ Department of Nutrition, University of California, Davis, CA, USA \\ ${ }^{3}$ Harvest Plus, Washington, DC, USA \\ ${ }^{4}$ Helen Keller International, Dakar, Senegal
}

The role of zinc deficiency as an important cause of morbidity and impaired linear growth has prompted the need to identify indicators of population zinc status. Three indicators have been recommended - prevalence of zinc intakes below the estimated average requirement (EAR), percentage with low serum zinc concentrations, and percentage of children aged $<5$ years who are stunted. This review outlines steps to estimate the prevalence of inadequate intakes, and confirm their validity based on the EARs set by International Zinc Nutrition Collaborative Group. Next, the appropriateness of serum zinc as a biochemical marker for population zinc status is confirmed by a summary of: (a) the response of serum zinc concentrations to zinc intakes; (b) usefulness of serum zinc concentrations to predict functional responses to zinc interventions; (c) relationship between initial serum zinc and change in serum zinc in response to interventions. Height- or length-for-age was chosen as the best functional outcome after considering the responses of growth, infectious diseases (diarrhoea, pneumonia), and developmental outcomes in zinc supplementation trials and correlation studies. The potential of other zinc biomarkers such as zinc concentrations in hair, cells, zinc-metalloenzymes, and zinc-binding proteins, such as metallothionein, is also discussed. Molecular techniques employing reverse transcriptase (RT)-polymerase chain reaction to measure mRNA in metallothionein and ZIP1 transporter hold promise, as do kinetic markers such as exchangeable zinc pools (EZP) and plasma zinc turnover rates. More research is needed to establish the validity, specificity, sensitivity, and feasibility of these new biomarkers, especially in community-settings.

Serum zinc: Low zinc intakes: Stunted children

Zinc is required for the activity of over 200 enzymes involved in most major metabolic pathways, and thus is necessary for a wide range of biochemical, immunological, and clinical functions. As a result, multiple functions in the body are affected by zinc deficiency including physical growth, immune competence, reproductive function, and neuro-behavioural development. Hence, in severe zinc deficiency, a wide range of disturbances occur including impaired growth, defects in the immune system, dermatitis, diarrhoea, delayed sexual and bone maturation, impaired taste acuity, and behavioural changes ${ }^{(1)}$. Assessment of marginal zinc deficiency, however, is more difficult because of the absence of frank clinical signs, and reliable sensitive and specific laboratory indicators.

A major factor associated with the development of zinc deficiency in populations is inadequate intakes of dietary zinc. Additional exacerbating factors include high physiological requirements for zinc (e.g., during infancy, adolescence, pregnancy, and lactation), and/or excessive losses arising from diarrhoea, specific disease states (e.g., coeliac disease, Crohn's diseases, short bowel syndrome, cystic fibrosis) and treatment with certain drugs (e.g., penicillamine, thiazide, and glucagon $)^{(2)}$. Unlike many other nutrients, there is no functional reserve or body store of available zinc, except possibly among infants, who may be able to draw on hepatic zinc accumulated during gestation ${ }^{(3)}$. Hence, when dietary intakes are inadequate, the growth rate in children, or rate of zinc excretion among adults, is reduced in an effort to conserve tissue zinc levels and maintain homeostasis. At this stage, there are no further biochemical or functional changes. However, when zinc deficiency is more severe, metabolic changes develop rapidly. Zinc balance becomes negative, with a net loss of zinc from a small rapidly exchangeable zinc pool, resulting in general tissue dysfunction ${ }^{(4)}$.

This review describes three indicators recommended by WHO/UNICEF/IAEA/IZINCG ${ }^{(5)}$ for assessing zinc status at the population level and evaluating nutrition interventions designed to combat zinc deficiency. They include the prevalence of usual zinc intakes below the estimated average requirement (EAR), percentage of the population with low serum zinc concentrations, and percentage of children less than 5 years of age with length- or height-for-age less than $-2.0 \mathrm{SD}$ below the age-specific median of the reference population. For each indicator, a cutoff for the prevalence considered indicative of elevated risk and of public health concern is given, at which level an intervention to improve population zinc status is warranted. The potential usefulness of other zinc biomarkers to assess zinc status, especially in community settings, is also discussed. 


\section{Dietary zinc intakes}

In Western countries, inadequate intakes of dietary zinc are frequently associated with low energy intakes, often induced by concerns about body weight coupled with a sedentary lifestyle $^{(6)}$ and/or poor food selection patterns. The latter may be linked with low intakes of flesh foods, concomitant with high intakes of unrefined cereals, nuts and legumes, a pattern often prompted by economic, ethical, and/or ecological concerns, as well as perceived health benefits ${ }^{(7)}$. Such a food consumption pattern is likely to compromise the bioavailability of dietary zinc. Plant-based foods contain high levels of phytic acid, a potent inhibitor of zinc absorption that forms insoluble $\mathrm{Zn}$-phytic acid complexes in the intestine ${ }^{(8)}$. Hence, population groups most at risk of inadequate intakes of dietary zinc in Western countries include vegetarians ${ }^{(9,10)}$, as well as the elderly ${ }^{(11)}$ and preschool children, who also frequently consume small amounts of flesh foods ${ }^{(12-14)}$.

Estimates of the prevalence of inadequate intakes of dietary zinc in a population can be used to assess the relative magnitude of the risk of zinc deficiency in the population, classify subpopulations at elevated risk, and identify dietary patterns that contribute to inadequate zinc intakes. Details of the steps required to assess the prevalence of inadequate intakes of zinc in a population are available in a technical brief compiled by the International Zinc Nutrition Consultative Group (IZiNCG) ${ }^{(15)}$. Briefly, the process involves five steps: (i) selecting a representative sample of the population; (ii) measuring food intake using either a weighed food record or a 24-hour recall, preferably on at least two non-consecutive days on each individual in the population sampled, or on at least a subsample of individuals (30-40 individuals per stratum); (iii) calculating zinc and phytate intakes, and dietary phytate:zinc molar ratios for each individual using an appropriate food composition database ${ }^{(16)}$; (iv) adjusting the distribution of observed zinc intakes to represent usual zinc intakes by removing the variability introduced by day-to-day variation in an individual's zinc intake; and (v) applying the EAR cut-point method to estimate the prevalence of usual zinc intakes below the EAR. A specialized software program (e.g., PC-SIDE, Iowa State University, Department of Statistics and Statistical laboratory, Ames, Iowa, USA) is available and should be used to adjust the distribution of observed intakes to usual zinc intakes (i.e., step iv). The programme can be down loaded from: http://www.iastate.edu/. If the day-to-day within subject variation in zinc intakes is not removed using this specialized software program, then the variance of the intake distribution will be too large, resulting in a biased estimate of the proportion of individuals with intakes below the EAR.

In cases where only one day of intake data has been collected, then the true intra-individual variation cannot be assessed, so that the distribution of observed zinc intakes cannot be adjusted to usual intakes. Instead, a coefficient of variation $(\mathrm{CV})$ of usual zinc intakes can be assumed, before applying the EAR cut-point method using a cumulative distribution function such as CDF.NORM in SPSS; details are given by $\mathrm{Hotz}^{(17)}$. The value recommended by $\mathrm{IZiNCG}^{(15)}$ for this $\mathrm{CV}$ (as a percentage) is $25 \%$, and is derived from several data sets including the UK national survey of young people aged 4 to 18 years $^{(18)}$.
IZiNCG suggests that when $25 \%$ or more of the population have zinc intakes less than the EAR, the risk of zinc deficiency is elevated and of public health concern ${ }^{(15)}$. The EAR chosen for this assessment should take into account the estimated bioavailability of zinc in the habitual diet of the target group. At present, in many Western countries, (e.g., in UK, US, Australia and New Zealand), a single EAR for zinc has been set based on a fixed bioavailability adjustment derived from the habitual mixed national diet. For lower income countries, however, where the compositions of the diets often vary markedly with socio-economic status, religion, and/or geographic location (i.e., urban or rural), the EAR selected should reflect the likely bioavailability of dietary zinc in the population group under study. $\mathrm{WHO} / \mathrm{FAO}^{(19)}$ use a semi-quantitative system to classify diets into three broad categories of low, moderate, and high bioavailability of zinc, based on three dietary variables: one absorption enhancer: protein from meat/fish/poultry; and two absorption inhibitors: high levels of calcium, particularly calcium salts, and the proportion of phytic acid to zinc in the whole diet. Note that the calcium content of most plant-based diets is too low to have any strong inhibitory effect. Exceptions might be diets based on tortillas prepared with lime-soaked maize, diets of lactoovovegetarians, and possibly diets of persons who chew betal nut with lime ${ }^{(16)}$. The IZiNCG categorizes diets into mixed or refined vegetarian diets and unrefined cereal-based diets, based on phytate: $\mathrm{Zn}$ molar ratios of $4-18$, and $>18$, respectively ${ }^{(1)}$. Hence, in order to select the appropriate EAR compiled by WHO/FAO or IZiNCG, data on the phytate content of the local foods of the population group under study must be compiled. The most comprehensive source of phytate values available is the WorldFood2 Dietary Assessment System. It is now in the public domain and can presently be obtained from the INFOODS website at: http://www.fao.org/ infoods/ software worldfood_en.stm. Phytate values for the USDA database are available from the University of Minnesota Nutrition Coordinating Center Nutrient Database.

Recently, the validity of the EARs set for zinc by IZiNCG for adults and children have been evaluated. First, the validity of the physiological requirements for absorbed zinc for adults was confirmed. This was achieved by examining data on biochemical and functional indicators of zinc status and/or zinc balance of adults participating mainly in controlled zinc depletion-repletion studies in order to establish the level of absorbed zinc intake necessary to maintain adequate zinc status. Hotz ${ }^{(17)}$ gives details of these studies; Seventeen data points were used from studies of men and seven data points for women. Next, the validity of the EARs for zinc (which depend in turn on the physiological requirement for absorbed zinc and the fractional absorption of zinc), were assessed by examining the concordance between studies reporting the predicted risk of zinc deficiency derived from prevalence estimates of inadequate intakes based on the EARs set by IZiNCG, and the prevalence of low serum zinc concentrations. Data from several small studies on adult non-pregnant $(n=6)$ and pregnant $(n=6)$ women, as well as from the most recent Mexican national nutrition survey ${ }^{(20)}$ were compiled. As an example, data for adult women in the Mexican nutrition survey (Fig. 1) show a reasonable concordance for the level of risk of zinc deficiency derived from the estimated prevalence of 


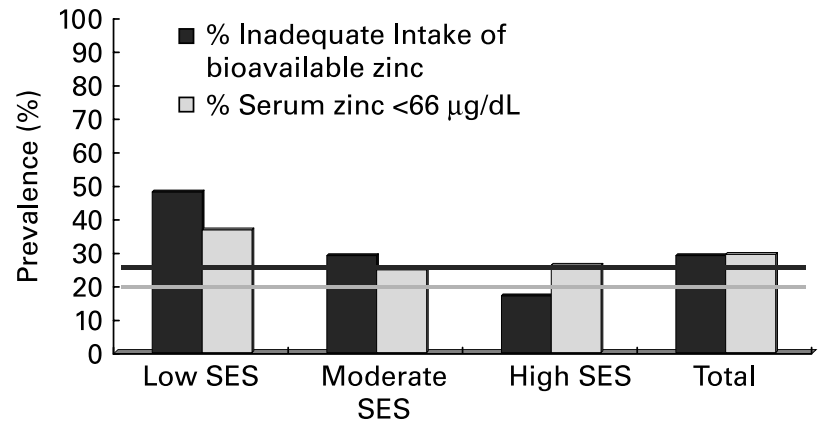

Fig. 1. Risk of $Z n$ deficiency in Mexican women assessed from dietary intake and serum $\mathrm{Zn}$ and its relation to socio-economic status (SES). Horizontal line at $25 \%$ prevalence represents the cutoff for high risk of inadequate zinc intake. Horizontal line at $20 \%$ prevalence represents the cutoff for high risk of low serum zinc concentrations. Data from the 1999 Mexican National Nutrition Survey ${ }^{(20)}$.

inadequate zinc intakes and the prevalence of low serum zinc concentrations.

Among studies in children, however, there is less consistency between the two estimates for the predicted risk of zinc deficiency, probably in part because of the method used to set the EARs for zinc for older infants and young children. Most agencies including $\mathrm{IZiNCG}^{(1)}$ and $\mathrm{WHO} / \mathrm{FAO}^{(19)}$ have used the factorial approach to set the EAR for zinc. However, the figure used for endogenous zinc losses for older infants and young children is extrapolated from that of adults. Hambidge and colleagues ${ }^{(21)}$ have recently suggested that it would be more appropriate to use differences in intestinal length than to use difference in body weight, to extrapolate adult data on zinc requirements to children. Estimates of zinc absorption from different diet types have also been derived from studies of adults, and the relationship between zinc intakes and phytate:zinc molar ratio of the diet has not been established directly from studies in children. Other possible confounding factors that might explain the inconsistent findings include the presence of infection, and the small, and non-representative nature of the study groups investigated. Hence, there is an urgent need for more studies on zinc requirements carried out directly among children.

\section{Serum or plasma zinc concentrations}

Zinc is transported in the serum bound principally to albumin $(70 \%)$. The remainder is bound tightly to $\alpha$-2-macroglobulin (18\%), and other proteins such as transferrin and caeruloplasmin. A very small amount (i.e., $\sim 0.01 \%$ ) is complexed with amino acids, especially histidine and cystine. Homeostatic mechanisms maintain serum zinc concentrations in healthy persons within a narrow range (about 12 to $15 \mu \mathrm{mol} / \mathrm{L} ; 78$ to $98 \mu \mathrm{g} / \mathrm{dL}$ ), even in the presence of markedly varying zinc intakes, regulated by two families of zinc transporters - ZIP (Zrt-, Irt-like protein) family and ZnT (SLC30) $^{(22)}$.

Measurement of serum or plasma zinc concentration is the only biochemical indicator recommended by WHO/UNICEF/ IAEA/IZiNCG to assess the zinc status of populations. The recommendation was made after examining the following at both the individual and population levels: (a) response of serum zinc concentrations to zinc intakes; (b) use of serum zinc concentrations to predict functional responses to zinc interventions; and (c) relationship between initial serum zinc and change in serum zinc in response to the intervention.

\section{Response of serum zinc concentrations to zinc intakes}

Hess and colleagues ${ }^{(23)}$ examined this relationship using data from 14 experimentally controlled zinc depletion-repletion studies on adults, zinc supplementation trials, and a few observational studies; details of these studies are given by Hess et al. ${ }^{(23)}$.

In severe dietary zinc restriction (i.e., $<2-3 \mathrm{mg} / \mathrm{d}$ ), there is a sharp decrease in serum zinc concentrations within about two weeks, with values returning to baseline levels within 1-2 weeks of commencing the repletion diet. Moreover, metabolic studies of Lowe et al. ${ }^{(24)}$ have confirmed that these changes in serum zinc during severe zinc restriction are associated with alterations in total body zinc content. Nevertheless, there is considerable inter-individual variation in the responses observed within and between studies for reasons that remain unclear. In more moderate dietary zinc restriction $(3-5 \mathrm{mg} / \mathrm{d})$, the response is more inconsistent, with a slight decrease or no change in serum zinc concentrations, possibly related to the duration of the dietary restriction and the phytate:zinc molar ratio of the diets.

Serum zinc concentrations have also shown a consistent and positive response in short-term zinc supplementation studies in well-nourished adults, or over periods ranging from 2-15 months in children. In the adult studies, levels have been shown to return to baseline shortly after discontinuation of the supplements. In contrast, the evidence from observational studies on free-living subjects that serum zinc concentrations reflect usual zinc intakes is less convincing, in part because so few studies have characterized usual zinc intakes appropriately. In addition, technical and biological factors, known to influence serum zinc concentrations, have not always been taken into account, and thus may have confounded the interpretation of the measurement ${ }^{(2)}$. Indeed, only a few small observational studies and two national nutrition surveys, one in the United Kingdom ${ }^{(18)}$ and the other in Mexico ${ }^{(20)}$ have reported relationships, albeit weak, between zinc intakes ${ }^{(18)}$, dietary indicators of absorbable zinc (e.g., phytate:zinc molar ratios $)^{(9,20)}$, or indicators of dietary quality (e.g., inclusion or exclusion of red meat) ${ }^{(25)}$ and serum zinc concentrations.

Fig. 2 summarizes the likely relationship between mean usual dietary zinc intakes and mean serum zinc concentrations among adults based on data from both the experimental zinc depletion/repletion studies and zinc supplementation studies. Data on usual zinc intakes derived from representative samples of U.S adult males in the Continuing Survey of Food Intake by Individuals (CSFII) cross-sectional survey ${ }^{(26)}$ and serum zinc concentrations from adult males participating in NHANES II ${ }^{(27)}$ are also included for comparison.

Based on this compilation of data, serum zinc concentrations fall sharply when dietary zinc intakes are less than $\sim 2$ to $3 \mathrm{mg} / \mathrm{d}$, but rise slightly but continuously when intakes are greater than 2 to $3 \mathrm{mg}$, reaching a plateau when zinc intakes reach $\sim 25$ to $30 \mathrm{mg} / \mathrm{d}$. Interestingly, a similar pattern has been reported for fractional zinc absorption when it has been measured with increasing daily doses of supplemental 


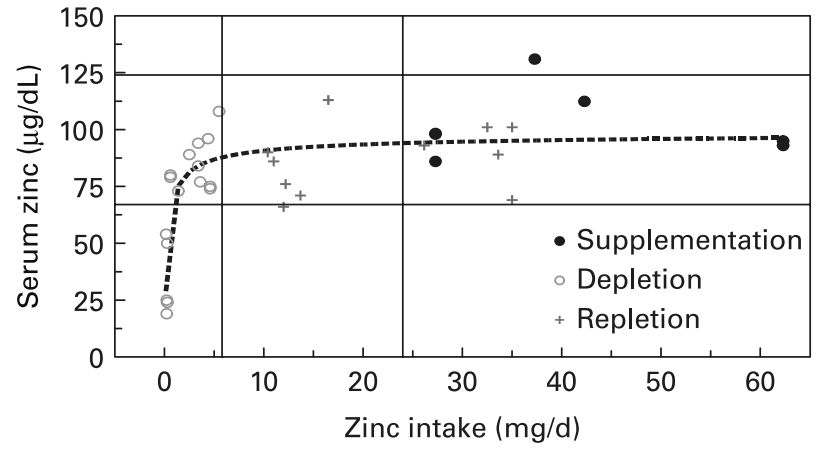

Fig. 2. Relation between mean dietary $\mathrm{Zn}$ intake and mean serum $\mathrm{Zn}$ from multiple adult studies. Data compiled from multiple studies of dietary zinc restriction (०) and repletion (+), studies of short-term and longer-term supplementation $(\bullet)$, and data on the usual zinc intakes of a representative sample of US adult men (CSFII) and the observed range of zinc concentrations among another representative sample of US adult men (NHANES II) ${ }^{(23)}$.

zinc. Again, a plateau of net zinc absorption was reached with doses of supplemental zinc of about $20 \mathrm{mg} \mathrm{Zn} \mathrm{per} \mathrm{day}{ }^{(28)}$. Taken together, the data shown in Fig. 2 suggest that the distribution of serum zinc concentrations in a population reflects the usual dietary zinc intakes of individuals in the population. This means that in populations with a high prevalence of inadequate zinc intakes, there will be a greater prevalence of low serum zinc concentrations. Hence, prevalence of low serum zinc concentration can be used to indicate risk of zinc deficiency in a population.

\section{Use of serum zinc concentrations to predict functional} responses to zinc interventions

The usefulness of serum zinc to predict a functional response to zinc interventions has been investigated at both the individual and population level by using a pooled analysis of nine studies, and an updated combined analysis of 24 zinc supplementation studies conducted on pre-pubertal children in lower-income countries, respectively. Data on growth were available from eight of the nine studies in the pooled analysis, but for diarrhoea and acute lower respiratory infection (ALRI), only four and two studies respectively, provided the necessary data; Hess et al. ${ }^{(23)}$ give details of each study. A separate analysis of covariance was conducted for each study and outcome variable, with treatment group (zinc or control), initial serum zinc concentration of each subject, and the interaction of these two main effects as possible explanatory variables. Results indicated that serum zinc concentrations of young children at the individual level do not predict their growth or morbidity response to zinc supplementation, although more data from populations with higher rates of growth stunting, and which include morbidity as an outcome, are needed to address this hypothesis conclusively. In only two of the studies were the mean initial height-for-age Z-scores of the children less than -1.5

At the population level, random-effects meta-regression analyses was used to examine the relationship between the mean serum zinc concentrations and effect sizes for change in height, change in weight, and change in weight-for-height. Results are shown in Figs. 3-5.

It appears that the mean serum zinc concentrations of the study population at baseline are negatively associated with

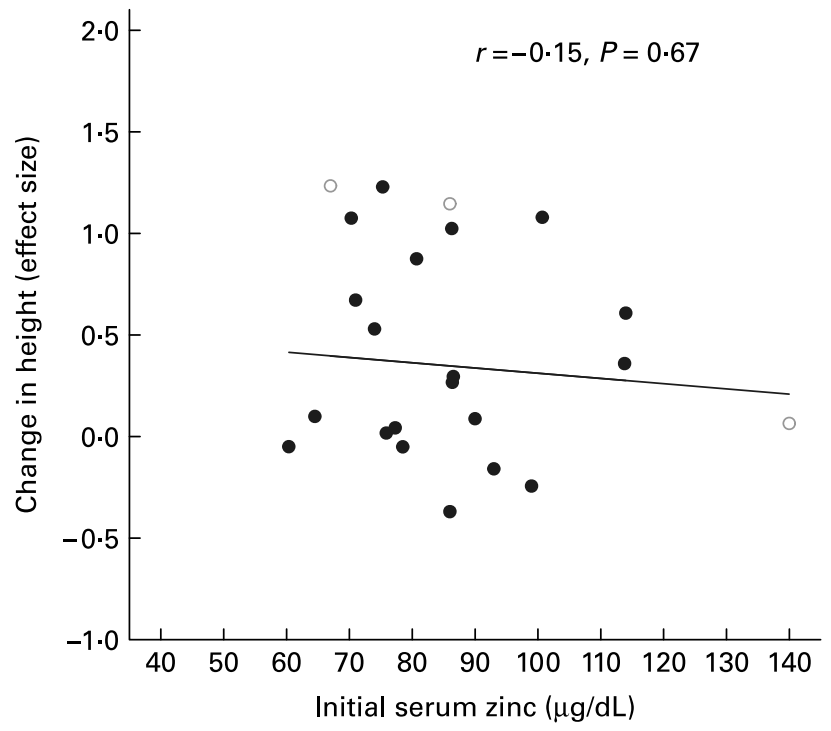

Fig. 3. Relation between mean initial serum zinc concentrations and effect size for mean change in height following zinc supplementation in 22 intervention trails. $(\bullet)$, studies in non-severely malnourished children; $(\circ)$, studies in severely malnourished children ${ }^{(23)}$.

the magnitude of growth response to zinc supplementation, particularly for weight gain, as indicated by changes in weight $(P=0.071)$ and weight-for-height $\mathrm{Z}$-score $(P=0.023)$, although the relationship for height was non-significant. Hence, mean serum zinc concentration for the population may be useful for predicting the growth response of a population to an intervention.

Relationship between initial serum zinc and change in serum zinc in response to the intervention

Data from the pooled analyses were also used to investigate change in serum zinc concentration in relation to the initial

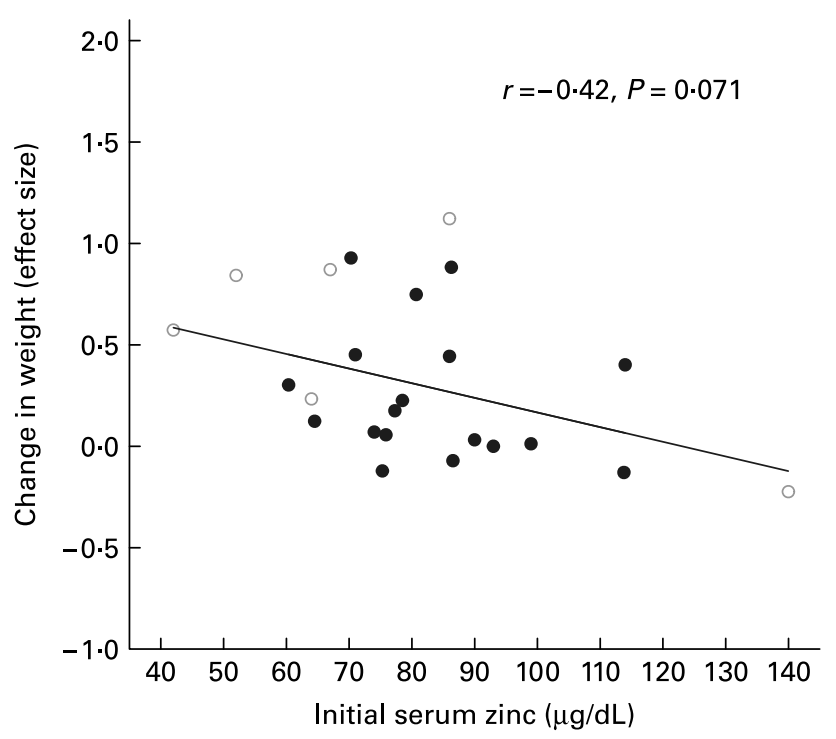

Fig. 4. Relation between mean initial serum zinc concentration and effect size for mean change in weight following zinc supplementation in 24 intervention trials. $(\bullet)$, studies in non-severely malnourished children; $(\circ)$, studies in severely malnourished children ${ }^{(23)}$ 


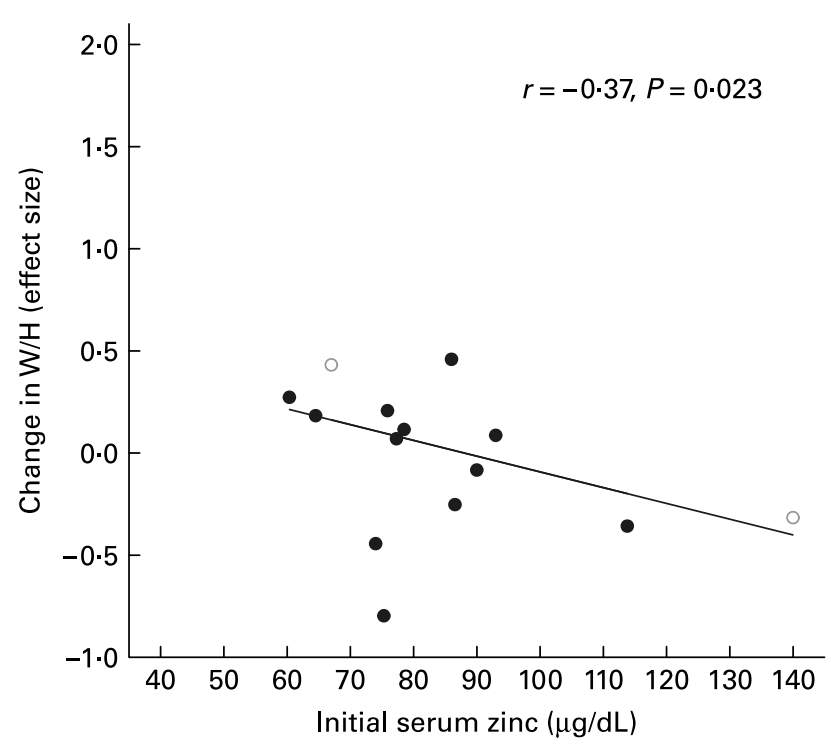

Fig. 5. Relation between mean initial serum zinc concentration and effect size for mean change in weight-for-height following zinc supplementation in 14 intervention trials. (•), studies in non-severely malnourished children; (०), studies in severely malnourished children ${ }^{(23)}$.

serum zinc value. In eight of the nine studies, a significant and positive effect of zinc supplementation on change in serum zinc concentrations was found, irrespective of the initial value $^{(23)}$. These findings confirm that a change in serum zinc from baseline values can be used as evidence of a successful delivery of an intervention, but should not be construed as evidence of pre-existing zinc deficiency. Nevertheless, there was only one significant interaction between treatment group and initial serum zinc concentration suggesting that the absolute effect of supplementation in each study was generally constant, irrespective of the individuals' initial level of serum zinc. It is notable that in almost all of the studies, a significant negative relationship was observed between initial serum zinc and change in concentration of this variable during supplementation in both the intervention and control groups, a phenomenon probably attributed to regression to the mean.

Positive effects of zinc supplementation on mean serum zinc concentrations have also been reported in a previously published meta-analysis of 15 studies of child growth ${ }^{(29)}$, and a more recent meta-analysis of nine studies in pregnant women $^{(23)}$. Again, in the meta-analysis, there was overall a significant and positive effect of zinc supplementation on the mean serum zinc concentrations of both the children and the pregnant women, with an overall effect size of $0.820 \mathrm{SD}$ units $(95 \%$ confidence interval, 0.499 to $1.14 \mathrm{SD}$ ) and 0.200 SD units (95\%CI, 0.051 to $0.348 \mathrm{SD})$, respectively.

\section{Reference data for serum zinc concentrations}

To interpret the level of risk of zinc deficiency at the population level based on serum zinc concentrations, cutoffs for serum zinc have been developed ${ }^{(27)}$. These are based on serum zinc data from a representative sample of persons aged 3 to 74 years of age from the US NHANES II survey, and represent the $2 \cdot 5$ th percentile of serum zinc concentrations for presumably healthy well-nourished males and females aged $<10 \mathrm{y}$ and $\geq 10 \mathrm{y}$ (by fasting status) and time of sampling
(Table 1). In this reanalysis, data for subjects with conditions significantly affecting serum zinc concentrations were excluded. These were subjects with low serum albumin $(<35 \mathrm{~g} / \mathrm{L})$, an elevated white blood cell count, using oral contraceptives, hormones or steroids, or experiencing diarrhoea. The lower cutoffs for boys and girls aged 3 to 9 years were combined because the difference between the sexes was negligible. IZiNCG suggests that if $>20 \%$ of a population subgroup have serum zinc concentrations below the designated cutoff, then the subgroup is considered to be at risk of zinc deficiency.

Recently, the applicability of the cutoffs for children less than 3 years of age has been examined further because serum zinc concentrations were not measured in the US NHANES II survey. Based on data from four studies of healthy children less than five years of age $\mathrm{e}^{(27,30-32)}$, use of a single reference value based on the NHANES II data for all children $>1$ year of age was recommended, although a different cutoff may be required for infants.

Only limited data $(n=61)$ were available on serum zinc concentrations for pregnant women in the US NHANES II survey. Because serum zinc concentrations decrease during the course of pregnancy in response to haemodilution and/or hormonal changes, or as a result of a normal physiological adjustment to pregnancy, lower cutoffs were derived for each trimester of pregnancy; these are also presented in Table 1. More data are urgently required to generate more reliable cutoffs for serum zinc concentration during pregnancy and for infants 0 to 12 months of age.

Care must be taken during the collection and preparation of blood samples for analyses of serum zinc concentrations, as noted earlier. Readers are advised to consult the technical brief prepared by $\mathrm{IZiNCG}^{(33)}$ that summarizes the recommended procedures to be used and the variables that must be measured or taken into account when interpreting the results. Table 2 summarizes both the technical and biological factors known to influence serum zinc concentrations.

\section{Functional indicators of zinc status}

Functional indicators aim to measure the extent of the functional consequences of zinc deficiency and hence, have greater biological significance than the two indicators reviewed

Table 1. Suggested lower cutoffs (2.5\% percentiles) for the assessment of serum zinc concentration in population studies, derived from NHANES $\|^{(27)}$

\begin{tabular}{|c|c|c|c|}
\hline & \multicolumn{3}{|c|}{ Lower cutoffs for serum $\mathrm{Zn} \mu \mathrm{g} / \mathrm{dL}(\mu \mathrm{mol} / \mathrm{L})^{*}$} \\
\hline & $\begin{array}{c}\text { Children } \\
<10 \mathrm{yr}\end{array}$ & $\begin{array}{c}\text { Females } \\
\geq 10 \mathrm{yr}\end{array}$ & $\begin{array}{l}\text { Males } \\
\geq 10 \mathrm{yr}\end{array}$ \\
\hline Morning fasting $†$ & NA & $70(10 \cdot 7)$ & $74(11.3)$ \\
\hline Morning nonfasting & $65(9.9)$ & $66(10 \cdot 1)$ & $70(10 \cdot 7)$ \\
\hline Afternoon & $57(8 \cdot 7)$ & $59(9 \cdot 0)$ & $61(9 \cdot 3)$ \\
\hline $\begin{array}{l}\text { 1st Trimester } \\
\text { 2nd/3rd Trimester }\end{array}$ & & $\begin{array}{l}\text { Pregnancy } \\
56(8 \cdot 6) \\
50(7 \cdot 6)\end{array}$ & \\
\hline
\end{tabular}

${ }^{*}$ Conversion factor: $\mu \mathrm{mol} / \mathrm{l}=(\mu \mathrm{g} / \mathrm{dL}) / 6.54$.

†Based on subjects $\geq 20 \mathrm{yr}$; NA: not available. Subjects with: low serum albumin; elevated WBCC; current diarrhoea; using oral contraceptives etc, were excluded. 
Table 2. Technical and biological factors affecting serum/plasma zinc concentrations

\begin{tabular}{|c|c|}
\hline Technical factors & Biological factors \\
\hline Adventitious contamination & Fasting/ non-fasting state \\
\hline $\begin{array}{l}\text { Refrigeration of blood after } \\
\text { collection }\end{array}$ & Diurnal and circadian variation \\
\hline $\begin{array}{l}\text { Position of subject - } \\
\text { recumbent or sitting }\end{array}$ & Infection and inflammation \\
\hline $\begin{array}{l}\text { Length of time prior to } \\
\text { blood separation }\end{array}$ & Age; sex \\
\hline Hemolysis & $\begin{array}{l}\text { Use of oral contraceptive } \\
\text { agents, hormones, steroids } \\
\text { Physiological state: rapid growth } \\
\text { pregnancy } \\
\text { Concurrent nutrient deficiencies } \\
\quad \text { (protein; vitamin A) } \\
\text { Weight loss } \\
\text { Disease states: e.g., marasmus }\end{array}$ \\
\hline
\end{tabular}

above. Further, the tests are less invasive, often easier to perform, and more directly related to disease mechanisms or health status than measurement of biochemical indicators such as serum zinc. Because the specificity of functional indicators is generally poor, they should be evaluated by their response to zinc supplementation in randomized controlled trials (RCTs). However, this approach is expensive because a large number of subjects is needed and there is a long delay before a measurable response can be detected.

Fischer Walker and Black ${ }^{(34)}$ examined whether functional indicators, notably infectious diseases, growth, and developmental outcomes, can be used to assess risk of zinc deficiency in populations. They reviewed data from RCTs of zinc supplementation, as well as correlation studies among children less than five years of age; details of each trial are summarized $^{(34)}$. Based on the evidence from 21 RCTs for the treatment and 25 RCTs for the prevention (both short-course and long-term daily or weekly supplementation) of diarrhoea and/or pneumonia and/or malaria, they concluded that zinc supplementation decreases the incidence and prevalence of both diarrhoea and pneumonia. Nevertheless, because the prevalence of these two infectious diseases is modified by the level of exposure to infectious agents, Fischer-Walker and Black cautioned that these functional indicators are probably only useful for identifying populations or sub-populations likely to be at elevated risk for zinc deficiency but are not useful for quantifying the prevalence of zinc deficiency in the population.

In relation to growth as a functional indicator, 28 zinc supplementation RCTS of children from birth to 17 years were examined. Of these, 21 reported a positive effect of zinc on at least one measured indicator of growth and seven reported no effect. These findings are consistent with an earlier metaanalysis of RCTs of zinc supplementation among pre-pubertal children by Brown et al. ${ }^{(29)}$, which was up-dated by FischerWalker and Black ${ }^{(34)}$. These investigators also confirmed that the greatest effect of zinc supplementation on linear growth can be expected among children with low HAZ scores at recruitment, irrespective of age of the children or whether they are from a developed or less-developed country.

Based on these analyses, height- or length-for-age was again selected as the functional growth outcome of choice for estimating zinc deficiency in populations. It is used in routine health and nutrition monitoring activities, standardized methods are available to measure it, and growth reference data are available. Finally, length- or height-for-age is likely to be the primary response to increased zinc intake, whereas gain in weight is likely to arise as a result of increased linear growth. Risk of zinc deficiency is considered to be of public health concern when the prevalence of low height- or length-for-age among children aged less than five years is $>20 \%$.

Seven RCTs of zinc supplementation which have included an indicator of child development were reviewed, each involving infants $<1$ year of age, and a zinc supplementation period of greater than 8 weeks. The basic development indicators used were Bayley Scales of Infant Development, Psychomotor Development Index, and Motor Development Index. In general, because the effects of zinc deficiency on child development were inconsistent and difficult to measure, child development was not considered a useful indicator of population zinc status.

\section{Other biomarkers of zinc status}

\section{Hair zinc concentrations}

The use of hair zinc concentrations as an indicator of zinc status has been controversial ${ }^{(35)}$. Available evidence suggests that during childhood, low hair zinc concentrations reflect chronic suboptimal zinc status, when the confounding effect of protein-energy malnutrition is absent. Low hair zinc concentrations in children have been found in several studies to be associated with other indices of sub-optimal zinc status such as impaired taste acuity, low growth percentiles, and high dietary phytate: $\mathrm{Zn}$ molar ratios ${ }^{(2)}$.

Hair zinc concentrations vary with age, sex, season, hair growth rate, severity of malnutrition, and possibly hair colour and other hair cosmetic products. Hence these factors must always be considered when interpreting the results. Standardized methods for the collection, washing, and analysis of hair samples must be used, and a certified reference material to assess the accuracy of the analytical method. A reference material for human hair is available from the Institute for Reference Materials and Measurements in Belgium ${ }^{(2)}$. More work is required to establish age and sex-specific cutoffs for hair zinc concentrations in children. Whether hair zinc is a valid index of chronic suboptimal zinc status among adults is uncertain ${ }^{(36)}$, and more studies are required.

\section{Zinc concentrations in cells}

Zinc concentrations in various cell types, including erythrocytes, platelets, leucocytes, and neutrophils have been investigated for their potential as indicators of zinc status. They provide an assessment of zinc status over a longer time period compared to that of the rapidly turning over plasma pool $^{(2)}$. However, investigations of their usefulness based on experimentally controlled zinc depletion-repletion studies ${ }^{(37)}$ and prolonged supplementation with high doses of zinc (e.g., $50 \mathrm{mg} / \mathrm{d}$ ) have yielded mixed results. Indeed, in some, during the zinc depletion phase, no response by erythrocyte or leucocyte zinc concentrations have been noted, even though there has been evidence of functional zinc deficiency, 
based on impaired taste acuity and immune function ${ }^{(37)}$. Further, there are neither standardized units for the expression of zinc concentrations in these cells, nor established reference values for the assays, making comparisons among studies and interpretation of the results difficult ${ }^{(38)}$. Additional factors limiting their use in community-based studies, particularly for paediatric populations, are the relatively large volumes of blood required for the assay, and the difficulties of separating leucocytes and other specific cell types under field conditions.

\section{Zinc metalloenzymes and zinc-binding proteins}

Several zinc metalloenzymes have been investigated as possible biomarkers of zinc status in plasma, erythrocytes, erythrocyte membranes, or in specific cell types. They include alkaline phosphatase (EC 3.1.3.1), $\delta$-amino-levulinic acid dehydratase (EC 4.2.1.24), angiotensin-1-converting enzyme (EC 3.4.15.1), $\alpha$-D-mannosidase (EC 3.2.1.24), extra-cellular superoxide-dismutase (EC-SOD), nucleoside phosphorylase (EC 2.4.2.1) and ecto purine 5'nucleotidase (EC 3.1.3.5). Of these enzymes, the activity of alkaline phosphatase in serum, erythrocytes, or erythrocyte membranes has been most frequently studied, but results have been inconsistent, especially in studies in community settings, probably compromised in part by the poor specificity of this enzyme. In general, the activity of alkaline phosphatase is reduced in severe zinc deficiency states $^{(39,40)}$ but not in more moderate zinc deficiency ${ }^{(41)}$. In contrast, the activity of ecto purine $5^{\prime}$ nuecleotidase in plasma or lymphocytes may be promising and warrants further study. Positive responses in plasma ecto purine $5^{\prime}$ nuecleotidase to changes in zinc intakes in zinc depletion-repletion studies, in some cases over relatively short time periods ${ }^{(42-44)}$, have been reported, although these findings are not consistent ${ }^{(41)}$. In another study, for example, the activity of the enzyme in

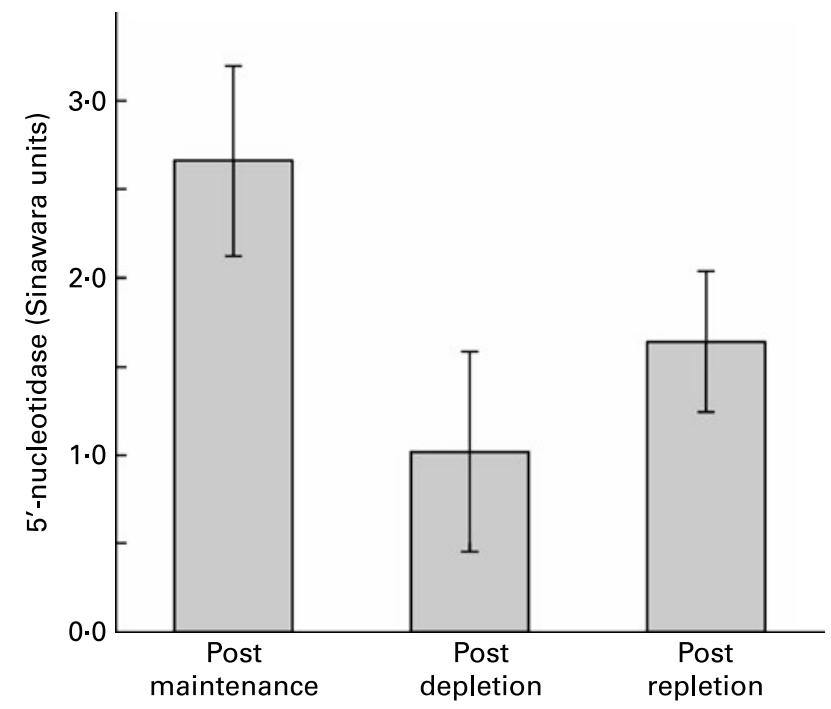

Fig. 6. Changes in plasma ecto purine $5^{\prime}$-nucleotidase before (post maintenance) and after 15 days of zinc depletion (post depletion) followed by $6 \mathrm{~d}$ of repletion (post repletion). For the maintenance phase, elderly subjects ( $n=15$; mean age $66.2 \pm 1.2 \mathrm{y}$ ) consumed a self-selected zinc-adequate diet with $16.4 \pm 1.44 \mathrm{mg} \mathrm{Zn/d}$ for $10-14$ days. For the zinc depletion, subjects consumed $3.97 \pm 0.21 \mathrm{mg} \mathrm{Zn/d}$ for 15 days and for the zinc repletion, subjects received $28 \mathrm{mg} \mathrm{Zn} / \mathrm{d}$ for $6 \mathrm{~d}^{(45)}$. lymphocytes (but not plasma) showed a positive response after 4-8 wk of mild zinc restriction ${ }^{(46)}$. This enzyme is derived from the CD73 cell-surface markers of B and T cells; Sunderman gives full details ${ }^{(47)}$.

In general, it appears that although a positive response has been observed in experimentally controlled zinc-depletionrepletion studies, often with severe dietary zinc restrictions, when these zinc-dependent enzymes are used in community settings where mild zinc deficiency is more likely to exist, their response is less consistent. Such inconsistencies may arise because of large between-subject variation and/or poor sensitivity, although other confounding factors affecting the specificity of their response cannot be excluded.

Of the zinc-binding proteins, metallothionein, a metal storage protein, is found in most tissues, especially liver, pancreas, kidney, and intestinal mucosa. Circulating levels of metallothionein in plasma respond to changes in zinc intake ${ }^{(4)}$, decreasing with low intakes. However, they increase in response to infection and stress. As a result, $\mathrm{King}^{(4)}$ recommends the use of a combination of serum zinc and serum metallothionein to assess zinc nutriture. Using this combination, a low level of both serum zinc and metallothionein would indicate a reduction in the size of the exchangeable zinc pool, as a result of a decrease in zinc intake. In contrast, low serum zinc concentrations in association with an elevated level of metallothionein could be indicative of redistribution of tissue zinc in response to infection and stress and not to suboptimal zinc status.

Measurement of metallothionein in erythrocytes has also been investigated as it appears to be responsive to both severe and moderate restrictions in zinc intake, rising again during the repletion phase, and, unlike levels in serum, is not responsive to stress ${ }^{(48)}$. Nevertheless, more research is required to establish the sensitivity and specificity of erythrocyte metallothionein as a valid measure of zinc status,

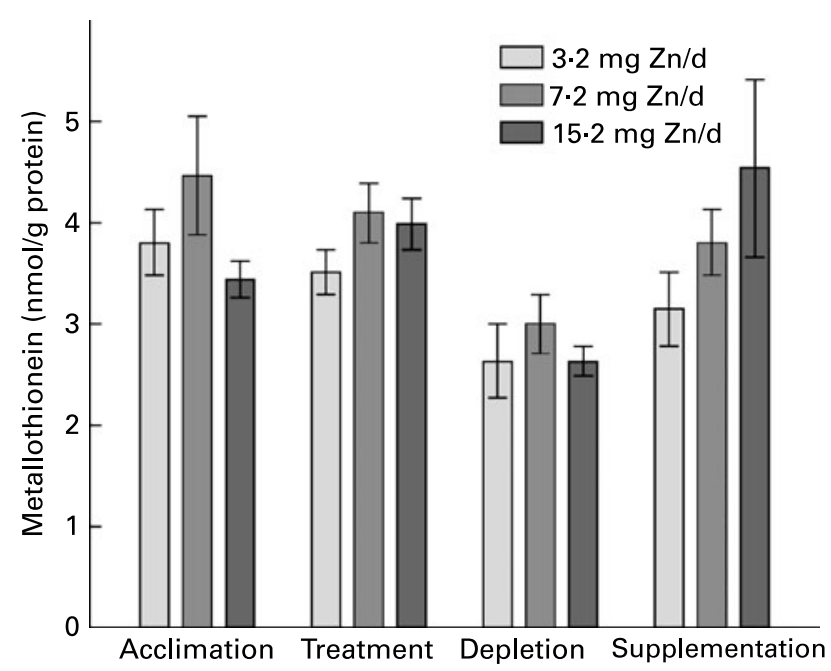

Fig. 7. Erythrocyte metallothionein concentrations of each treatment group during acclimation, depletion, and supplementation. For the acclimation phase, male subjects ( $n=15$; aged $22-35$ y) received diets providing $15 \mathrm{mg}$ $\mathrm{Zn} / \mathrm{d}$ for $7 \mathrm{~d}$. During the treatment phases, subjects were randomly divided into three groups ( $n=5$ per group) and received diets providing $3 \cdot 2,7 \cdot 2$ or $15.2 \mathrm{mg} \mathrm{Zn} / \mathrm{d}$ for $42 \mathrm{~d}$. All subjects were next provided with a diet with $0.55 \mathrm{mg} \mathrm{Zn} / \mathrm{d}$ for $12 \mathrm{~d}$ (depletion phase), followed by a supplementation

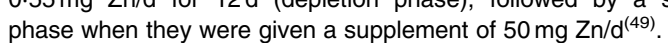


especially in community-based studies where the occurrence of mild zinc deficiency is more likely.

Thymulin is a zinc-containing polypeptide that activates $\mathrm{T}$ cells and is secreted by thymic epithelial cells. Levels of circulating thymulin in serum decrease in mild zinc deficiency, even when there is no change in serum zinc concentrations ${ }^{(50)}$.

\section{Molecular techniques}

Polymerase chain reaction assays are being used increasingly to measure mRNA for some of the proteins involved in zinc regulation. For example, metallothionein mRNA has been measured in a variety of tissues after zinc depletion and supplementation using reverse transcriptase (RT)-polymerase chain reaction (PCR). Metallothionein mRNA in lymphocytes appear to decrease markedly in response to mild zinc depletion, returning to baseline levels after repletion ${ }^{(51)}$, and to be elevated consistently in monocytes and erythrocytes post zinc supplementation ${ }^{(52,53)}$; an example is shown in Fig. 8. However, because metallothionein expression also responds to changes in other heavy metals besides zinc, such changes may not necessarily reflect changes in zinc intakes ${ }^{(54)}$. More research is needed on the effects of various stresses on this biomarker to assess its specificity, and to establish its validity as an index of zinc status in 'free-living' volunteers in community settings.

Two families of zinc transporters - ZNT and ZIP - in human lymphoblastoid cell have also been investigated using quantitative RT-PCR as potential indicators of zinc status. Two potential zinc indicators were identified - ZIP-1 and ZNT1 - of which only the expression of ZIP-1 in

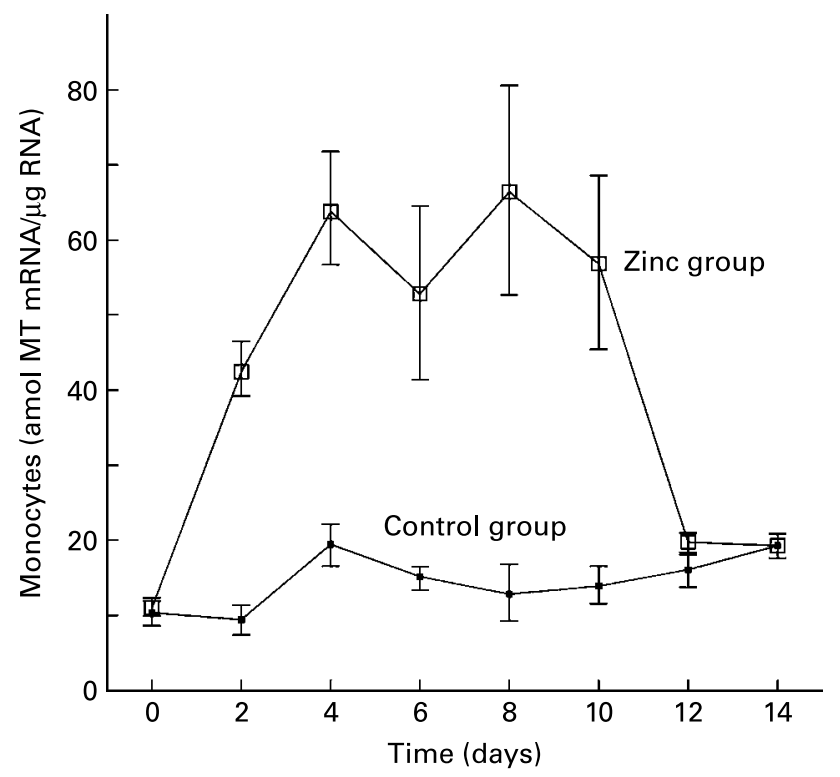

Fig. 8. Metallothionein (MT) mRNA levels in purified monocytes from control and zinc supplemented men. The subjects were given $15 \mathrm{mg} / \mathrm{d} \mathrm{Zn}$ or placebo for $10 \mathrm{~d}$ and no zinc supplementation for an additional $4 \mathrm{~d}$. Monocytes were purified from venous blood by NycoPrep 1.068 gradient centrifugation and were the source of the total RNA used for reverse transcription. MT mRNA was measured by competitive reverse transcription-polymerase chain reaction (CRT-PCR) and expressed as amol MT mRNA/ $\mu \mathrm{g}$ total RNA. Values are means $\pm \mathrm{SE}, n=8$. Zinc mean is significantly different from mean for control subjects for days $2-10$ inclusive ${ }^{(52)}$ leucocytes decreased significantly by $17 \%$ when women were supplemented with zinc for 27 days $(22 \mathrm{mg} \mathrm{Zn} / \mathrm{d})$. Hence, ZIP-1 appears to have potential as a biomarker of zinc status in humans ${ }^{(55)}$.

The effects of zinc supplements on genome health maintenance, cell death and mitogen response of peripheral blood lymphocytes has been investigated using the cytokinesisblock micronucleus (CBMN) cytome assay. Results appear promising, although studies with a randomized double-blind, placebo-controlled design are needed to confirm these preliminary findings ${ }^{(56)}$.

\section{Kinetic markers: pool sizes and turnover rates}

Isotope studies evaluating turnover rate in plasma or urine have identified a relatively small exchangeable pool of zinc (EZP), with a turnover of about 12.5 days. This rapid pool comprises the most metabolically active forms of zinc in the plasma, extracellular fluid, liver, pancreas, kidney, and intestine, which are mobilized for zinc-dependent functions ${ }^{(57)}$. The size of EZP is estimated from tracer- tracee disappearance curves using kinetic modeling software. Total EZP mass appears to respond to severe restrictions of dietary zinc (i.e., $<1 \mathrm{mg} / \mathrm{d}$ for $4-5$ weeks), resulting in a $36 \%$ reduction $^{(40)}$ but not to modest short-term changes in zinc intake (i.e., $4.6 \mathrm{mg} / \mathrm{day}^{(41)}$. Hence, the size of the EZP does not appear to be useful indicator for identifying short-term marginal zinc intakes.

Plasma zinc turnover rates have also been investigated as an indicator of zinc status. When the total body zinc content is reduced, fractional plasma zinc turnover rates are increased to meet tissue needs. Increases of about 150 to $\sim 200$ times per day have been observed in healthy men as a result of acute, severe zinc depletion (i.e., $0 \cdot 23 \mathrm{mg} / \mathrm{d}$ ) ${ }^{(40)}$, but not when it was more modest ${ }^{(41)}$. Further, in the study of acute severe zinc depletion repletion, when changes in kinetic markers were correlated with those of the biochemical indicators ${ }^{(40)}$, plasma zinc concentrations had the strongest relationship to net loss/gain of zinc from the body $\left(r^{2}=0 \cdot 826\right)$, followed by endogenous zinc excretion $\left(r^{2}=0.773\right)$ and plasma zinc flux $\left(r^{2}=0.766\right)$.

Currently, stable isotope studies involving kinetic markers are invasive, costly, complex, and time-consuming, making them more suitable for validating innovative and simpler zinc assessment techniques rather than as a routine tool. If the methodology can be simplified, however, kinetic markers could be useful for assessing zinc status in the future.

\section{Conclusions}

Development of a set of recommendations for indicators of population zinc status is a necessary step for generating prevalence data on zinc deficiency at the country level. The three indicators recommended for international use are: (a) percentage with low serum zinc concentrations, (b) prevalence of zinc intakes below the EAR, and (c) percentage of children less than 5 years of age with length- or heightfor-age less than $-2.0 \mathrm{SD}$ below the age-specific median of the reference population. As countries gain experience in using these indicators and their cutoffs to establish whether zinc deficiency is a public health problem, so their validity can be re-evaluated, and the cutoffs refined, where 
necessary. In the future, indicators of zinc status based on molecular or kinetic markers may be used, although at present more research is needed to establish their specificity, sensitivity, validity, and feasibility, especially for use in community-settings.

\section{Acknowledgements}

The authors acknowledge the contribution of Janet M. Peerson who developed the original figures that have been reproduced in this paper.

\section{References}

1. Hotz C \& Brown KH (2004) International zinc nutrition consultative group (IZiNCG) technical document \#1. Assessment of the risk of zinc deficiency in populations and options for its control. Food Nutr Bull 25, S99-S199.

2. Gibson RS (2005) Principles of Nutritional Assessment, 2nd ed. New York: Oxford University Press.

3. Zlotkin SH \& Cherian MG (1988) Hepatic metallothionein as a source of zinc and cysteine during the first year of life. Pediatr Res 24, 326-329.

4. King JC (1990) Assessment of zinc status. J Nutr 120, $1474-1479$.

5. WHO/UNICEF/IAEA/IZiNCG (2007) Report of a WHO/ UNICEF/IAEA/IZiNCG interagency meeting on zinc status indicators. Food Nutr Bull 28, S399-S483.

6. Houston MS, Summers SL \& Soltesz KS (1997) Lifestyle and dietary practices influencing iron status in university students. Nutr Res 17, 9-22.

7. Richardson NJ (1994) UK consumer perceptions of meat. Proc Nutr Soc 53, 281-287.

8. Lönnerdal B (2000) Dietary factors influencing zinc absorption. J Nutr 130, 1378S-1383S.

9. Donovan UM \& Gibson RS (1995) Iron and zinc status of young women aged 14 to 19 years consuming vegetarian and omnivorous diets. $J$ Am Coll Nutr 14, 463-472.

10. Hunt JR (2003) Bioavailability of iron, zinc, and other trace minerals from vegetarian diets. Am J Clin Nutr 78, 633S-639S.

11. Ma J \& Betts NM (2000) Zinc and copper intakes and their major food sources for older adults in the 1994-96 Continuing Survey of Food Intakes by Individuals (CSFII). J Nutr 130, $2838-2843$.

12. Smit-Vanderkooy P \& Gibson RS (1987) Food consumption patterns of Canadian preschool children in relation to zinc and growth status. Am J Clin Nutr 45, 609-616.

13. Skinner JD, Carruth BR, Houck KS \& Coletta F (1997) Longitudinal study of nutrient and food intakes of infants aged 2 to 24 months. JADA 97, 496-505.

14. Soh P, Ferguson EL, McKenzie JE, Skeaff S, Parnell W \& Gibson RS (2002) Dietary intakes of 6-24 month-old urban South Island New Zealand children in relation to biochemical iron status. Public Health Nutr 5, 339-346.

15. IZiNCG (International Zinc Nutrition Collaborative Group) (2007a) Determining the risk of zinc deficiency: assessment of dietary zinc intake. IZiNCG Technical Brief No. 03.

16. Gibson RS \& Ferguson EL (1999) An Interactive 24-h Recall Method for Assessing Intakes of Iron and Zinc in Developing Countries. Washington, DC: ILSI Press.

17. Hotz C (2007) Dietary indicators for assessing the adequacy of population zinc intakes. Food Nutr Bull 28, S430-S448.

18. Gregory J, Low S, Bates CJ, Prentice A, Jackson LV, Smithers G, Wenlock R \& Farron M (2000) National Diet and Nutrition
Survey: young people aged 4 to 18 years. Volume 1: Report of the Diet and Nutrition Survey. London: The Stationery Office.

19. WHO/FAO (World Health Organization/Food and Agriculture Organization) (2004) Vitamin and Mineral Requirements in Human Nutrition, 2nd ed. Geneva: World Health Organization.

20. Hotz C, Lowe NM, Araya M \& Brown KH (2003a) Assessment of the trace element status of individuals and populations. The example of zinc and copper. $J$ Nutr 133, 1563S-1568S.

21. Hambidge KM, Mazariegos M, Solomons NW, Westcott JE, Lei S, Raboy V, Grunwald G, Miller LV, Sheng X \& Krebs NF (2007) Intestinal excretion of endogenous zinc in Guatemalan school children. J Nutr 137, 1747-1749.

22. Liuzzi JP \& Cousins RJ (2004) Mammalian zinc transporters. Ann Rev Nutr 24, 151-172.

23. Hess SY, Peerson JM, King JC \& Brown KH (2007) Use of serum zinc concentration as an indicator of population zinc status. Food Nutr Bull 28, S403-S429.

24. Lowe NM, Woodhouse LR, Sutherland B, Shames DM, Burri BJ, Abrams SA, Turnland JR, Jackson MJ \& King JC (2004) Kinetic parameters and plasma zinc concentrations correlated well with net loss and gain of zinc from men. J Nutr 134, 2178-2181.

25. Gibson RS, Heath AL, Limbago ML, Prosser N \& Skeaff CM (2001) Are changes in food consumption patterns associated with lower biochemical zinc status among women from Dunedin, New Zealand? Br J Nutr 86, 71-80.

26. USDA (US Department of Agriculture) (1998) Agriculture Research Service. Continuing Survey of Food Intakes by Individuals 1994-1996. National Technical Information Service CD-Rom 2002 (NTIS Accession no. PB2000-500027, 2002), 1998.

27. Hotz C, Peerson JM \& Brown KH (2003b) Suggested lower cutoffs of serum zinc concentrations for assessing zinc status: reanalysis of the second National Health and Nutrition Examination Survey data (1976-1980). Am J Clin Nutr 78, 756-764.

28. Tran CD, Miller LC, Krebs NF, Lei S \& Hambidge KM (2004) Zinc absorption as a function of dose of zinc sulfate in aqueous solution. Am J Clin Nutr 80, 1570-1573.

29. Brown KH, Peerson JM, Rivera J \& Allen LH (2002) Effect of supplemental zinc on the growth and serum zinc concentrations of prepubertal children: a meta-analysis of randomized controlled trials. Am J Clin Nutr 75, 1062-1071.

30. Karr M, Mira M, Causer J, Earl J, Alperstein G, Wood F, Fett MJ \& Coakley J (1997) Age-specific reference intervals for plasma vitamins $\mathrm{A}, \mathrm{E}$ and beta-carotene and for serum zinc, retinol-binding protein and prealbumin for Sydney children aged 9-62 months. Int J Vitam Nutr Res 67, 432-436.

31. Van Biervliet S, Van Biervliet JP, Bernard D, Vercaemst R \& Blaton V (2003) Serum zinc in healthy Belgian children. Biol Trace Elem Res 94, 33-40.

32. Lockitch G, Halstead AC, Wadsworth L, Quigley G, Reston L \& Jacobson B (1988) Age- and sex-specific pediatric reference intervals and correlations for zinc, copper, selenium, iron, vitamins A and E, and related proteins. Clin Chem 34, 1625-1628.

33. IZiNCG (International Zinc Nutrition Collaborative Group) (2007b) Assessing population zinc status with serum zinc concentration. IZiNCG Technical Brief No. 02.

34. Fischer Walker CL \& Black RE (2007) Functional indicators for assessing zinc deficiency. Food Nutr Bull 28, S454-S479.

35. Hambidge KM (1982) Hair analyses: worthless for vitamins, limited for minerals. Am J Clin Nutr 32, 2532-2539.

36. Yokoi E, Egger NG, Ramanujam VMS, Alcock NW, Dayal HH, Penland JG \& Sandstead HH (2003) Association between plasma zinc concentration and zinc kinetic parameters in premenopausal women. Am J Physiol Endocrinol Metab 285, E1010-E1020.

37. Ruz M, Cavan KR, Bettger WJ \& Gibson RS (1992) Erythrocytes, erythrocyte membranes, neutrophils and platelets as 
biopsy materials for the assessment of zinc status in humans. Brit J Nutr 68, 515-527.

38. Thompson RPH (1991) Assessment of zinc status. Proc Nutr Soc 50, 19-28.

39. Sachdev HP, Mittal NK \& Yadav HS (1990) Oral zinc supplementation in persistent diarrhoea in infants. Ann Trop Paediatr 10, 63-69.

40. King JC, Shames DM, Lowe NM, Woodhouse LR, Sutherrland B, Abrams SA, Turnlund JR \& Jackson MJ (2001) Effect of acute zinc depletion on zinc homeostasis and plasma zinc kinetics in men. Am J Clin Nutr 74, 116-124.

41. Pinna K, Woodhouse LR, Sutherland B, Shames DM \& King JC (2001) Exchangeable zinc pool masses and turnover are maintained in healthy men with low zinc intakes. J Nutr 131, 2288-2294.

42. Bales CW, DiSilvestro RA, Currie KL, Plaisted CS, Joung H, Galanos AN \& Lin PH (1994) Marginal zinc deficiency in older adults: responsiveness of zinc status indicators. $J \mathrm{Am}$ Coll Nutr 13, 455-462.

43. Blostein-Fujii A, DiSilvestro RA, Frid D, Katz C \& Malarkey W (1997) Short-term zinc supplementation in women with on-insulin-dependent diabetes mellitus: effects on plasma $5^{\prime}$ nucleotidase activity insulin-like growth factor I concentrations and lipoprotein oxidation rates in vitro. Am J Clin Nutr 66, 639-642.

44. Davis CD, Milne DB \& Nielsen FH (2000) Changes in dietary zinc and copper affect zinc-status indicators of postmenopausal women, notably extracellular superoxide dismutase and amyloid precursor proteins. Am J Clin Nutr 71, 781-788.

45. Bales CW, DiSilvestro RA, Currie KL, Plaisted CS, Joung H, Galanos AN \& Lin PH (1994) Marginal zinc deficiency in older adults: responsiveness of zinc status indicators. $J \mathrm{Am}$ Coll Nutr 13, 455-462.

46. Meftah S, Prasad AS, Lee DY \& Brewer GJ (1991) Ecto $5^{\prime}$ nucleotidase $\left(5^{\prime} \mathrm{NT}\right)$ as a sensitive indicator of human zinc deficiency. J Lab Clin Med 118, 309-316.

47. Sunderman FW (1990) The clinical chemistry of 5'nucleotidase activity. Clin Chem 13, 903-910.
48. Grider A, Bailey LB \& Cousins RJ (1990) Erythrocyte metallothionein as an index of zinc status in humans. Proc Natl Acad Sci USA 87, 1259-1262.

49. Thomas EA, Bailey LB, Kauwell GA, Lee DY \& Cousins RJ (1992) Erythrocyte metallothionein response of dietary zinc in humans. J Nutr 122, 2408-2414.

50. Prasad AS, Meftah S, Abdallah J, Kaplan J, Brewer GJ, Bach JF \& Dardenne M (1988) Serum thymulin in human zinc deficiency. J Clin Invest 82, 1202-1210.

51. Allan AK, Hawksworth GM, Woodhouse LR, Sutherland B, King JC \& Beattie JH (2000) Lymphocyte metallothionein mRNA responds to marginal zinc intake in human volunteers. Br J Nutr 84, 747-756.

52. Cao J \& Cousins RJ (2000) Metallothionein mRNA in monocytes and peripheral blood mononuclear cells and in cells from dried blood spots increases after zinc supplementation of men. J Nutr 130, 2180-2187.

53. Sullivan VK, Burnett FR \& Cousins RJ (1998) Metallothionein expression is increased in monocytes and erythrocytes of young men during zinc supplementation. J Nutr 128, 707-713.

54. Saydam N, Adams TK, Steiner F, Schaffner W \& Freedman J (2002) Regulation of metallothionein transcription by the metal-reponseive transcription factor MTF-1. J Biol Chem 227, 20438-20445.

55. Andree KB, Kim J, Kirschke CP, Gregg JP, Pail H-Y, Joung H, Woodhouse L, King JC \& Huang L (2004) Investigation of lymphocyte gene expression for use as biomarkers for zinc status in humans. J Nutr 134, 1716-1723.

56. Fenech M (2007) The cytokinesis-block micronucleus (CBMN) cytome assay as a bioefficacy biomaker for zinc status. http:// www.fertilizer.org/ifa/publicat/PDF/2007_zinccrops2007_fenech. pdf (accessed Jan 2008).

57. Miller LV, Hambidge KM, Naake VL, Hong Z, Westcott JL \& Fennessey PV (1994) Size of the zinc pools that exchange rapidly with plama zinc in humams: alternative techniques for measuring and relation to dietary zinc intake. $J$ Nutr 124, $268-276$. 